\title{
Slope Mapping using Unmanned Aerial Vehicle (UAV)
}

\author{
Muhammad Farhan Zolkepli ${ }^{1}$, Norlinda Mohamad Rozar ${ }^{2}$, Mohd Fakhrurrazi Ishak ${ }^{3 *}$ \\ Mohamad Hazeem Sidik ${ }^{4}$, Nurul Amira Syuhada Ibrahim ${ }^{5}$, Muhammad Syamsul Imran Zaini \\ ${ }^{1,3,5,6}$ Faculty of Civil Engineering Technology, Universiti Malaysia Pahang, 26300 Kuantan, \\ Pahang, Malaysia \\ ${ }^{2}$ Faculty of Maritime Studies, Universiti Malaysia Terengganu, 21030 Kuala Nerus, Malaysia \\ ${ }^{3}$ Faculty of Entrepreneurship and Business, Universiti Malaysia Kelantan, Pengkalan Chepa, \\ 16100 Kota Bharu, Kelantan \\ 2akhrurrazi@ump.edu.my, ${ }^{3 *}$ norlinda.rozar@umt.edu
}

Article History: Received: 10 November 2020; Revised: 12 January 2021; Accepted: 27 January 2021; Published online: 05 April 2021

Abstract: This paper discusses the applications of unmanned aerial vehicle (UAV) for slope mapping and also its important
parameters including perimeter, area and also volume of certain selected area. With the development of modern technology,
the utilization of UAV to gather data for slope mapping becoming easier as it is quick, reliable, precise, cost-effective and
also easily to operate. Modern UAV able to take high quality image which essential for the effectiveness and nature of normal
mapping output such as Digital Surface Model (DSM) and Digital Orthophoto. This photo captured by UAV will later
transfer to commercial software to generate full map of study area. With the help of established software, the measurement of
selected study areas can be determined easily which can be considered as the main interest in this study. In addition, another
outcome of this study is, this modern method of mapping will be compare to traditional method of mapping which proven to
be more effective in term of low costing, low time consuming, can gather huge amount of data within short period of time,
low man power needed and almost no potential risk of hazardous effect to man.
Keywords: Mediation Effect Firm Performance, Reen Innovation, Firm Value Industry

\section{Introduction}

Nowadays, the instruments uses for data acquisition in geological topography have been rapidly improved. With the development of modern technology, the equipment used to gather all information related to earth surfaces becomes cheaper, smaller, accurate and can gather large number of data within a short period of time (Kumar et al., 2018, Bondarchuk, 2018). Unmanned aerial vehicles ('UAV's) are also known by many other names, such as, unmanned aircraft system ('UAS'), remotely piloted aircraft ('RPA'), micro air vehicle ('MAV') (Beretta et al., 2018).

These devices are light, mobile, easily to operate, completely automated and providing access to almost unavailable study areas. Advances in UAV technology have enabled the acquisition of high-resolution and realtime aerial images for photogrammetry (Park et al., 2019, Turner et al., 2016). An unmanned aerial vehicle (UAV) is normally an aircraft that launches and flies without a human onboard (Eid et al., 2013).

\subsection{Traditional Mapping}

As suggested by Ibrahim (2020), the first map was found in 2000 BC which is Babylon's clay tablets by Greeks and Romans. After that, the data was collected by surveyors in the field with later drawn to maps by cartographers with printers generating paper maps. The measurement of electronic distance (EDM) explained on how quick it makes proper distance measurements. It also provided way to find the location of the shooting plane, which reduces the amount of measurement needed to produce several type of maps. Table 1 shows the disadvantages of using traditional method of mapping.

Table 1. Disadvantages of mapping using traditional method (Ibrahim, 2020)

Author Types and Disadvantages

Fitzpatrick (2016)

Manned Aircraft (this method of mapping and volume consume lot of time, cost but less accurate) 
Muhammad Farhan Zolkepli, Norlinda Mohamad Rozar, Mohd Fakhrurrazi Ishak*, Mohamad Hazeem Sidik, Nurul Amira Syuhada Ibrahim, Muhammad Syamsul Imran Zaini

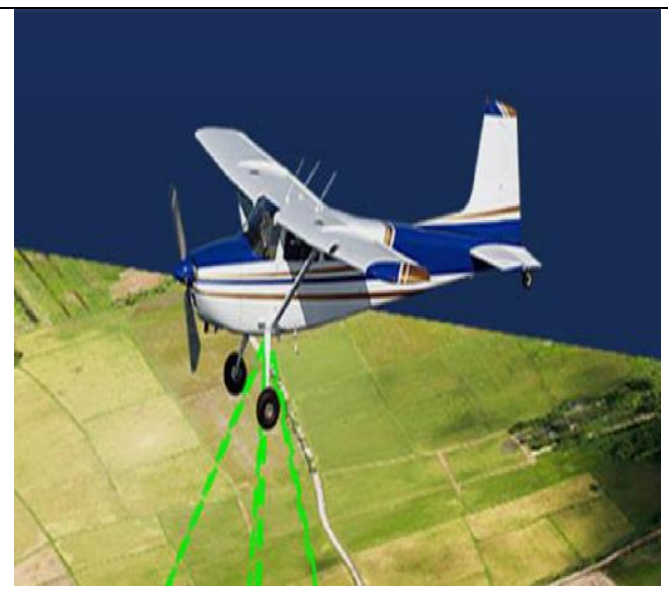

Laser Scanning Survey (Expensive, low quality mapping, and time consuming)

Beretta et al. (2018)

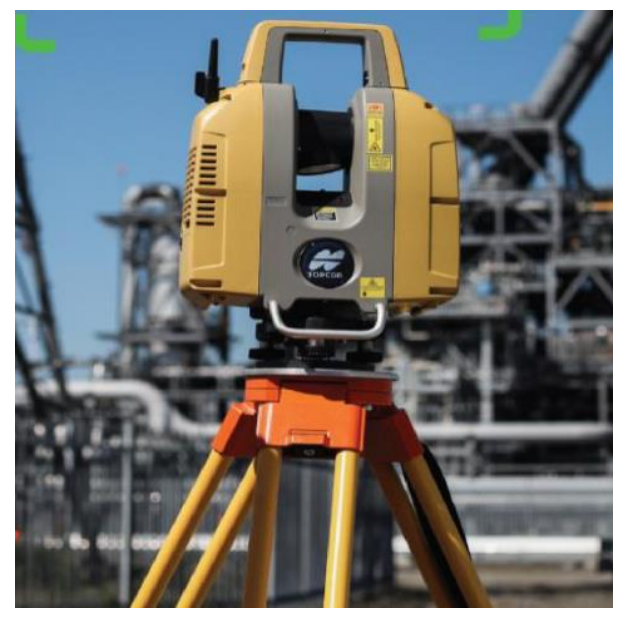

GPS Point Survey (Inaccurate and not very dense in information)

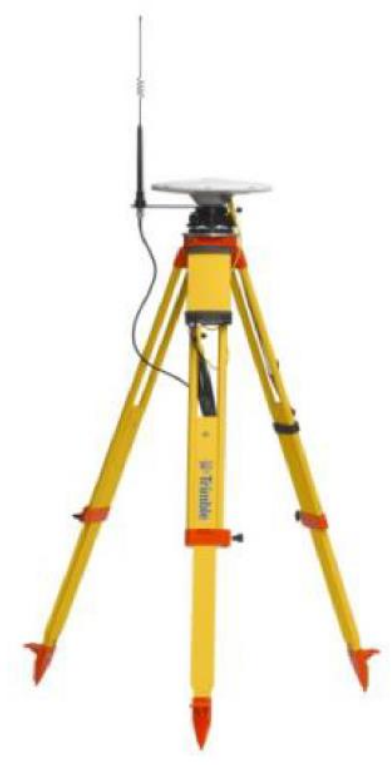

Siebert and Teizer (2014)
Tachymetry (Theodolite) Surveying (Time consuming, need a lot of workers and inaccurate in results) 


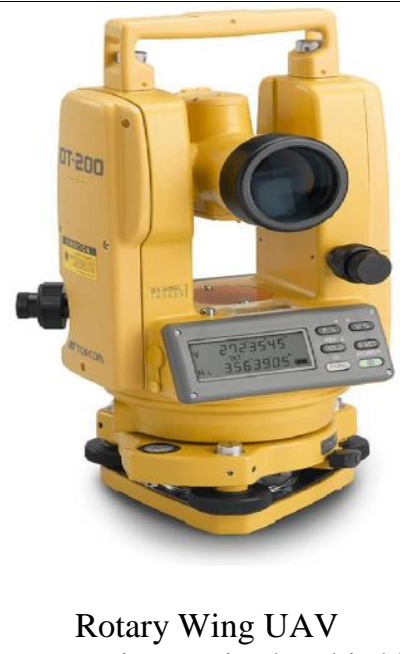

(High cost and time consuming. Noise level is high and need extreme magnetic field)

Tahar (2011);

Malehmir et al. (2017)

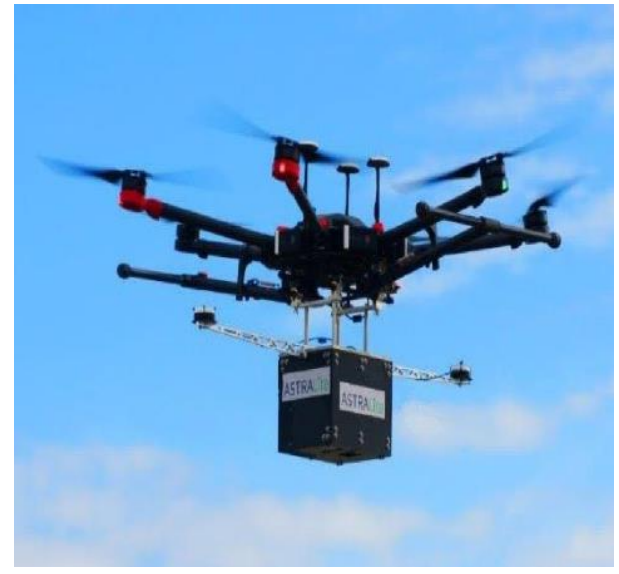

\subsection{Mapping Using Unmanned Aerial Vehicle (UAV)}

Recently, the use of unmanned aerial vehicle in research study and also commercial term are ending up progressively normal (Kumar et al., 2018). According to Ismail et al. (2018), geophysical surveys in mountains and natural terrains are normally challenging due to the site conditions, which may affect the quality of data acquisition. Unmanned aerial vehicle (UAV) or known as drone allow for the effectiveness of monitoring which cover large area of land and infrastructures within a very short time interval compare to conventional techniques (Tziavou et al., 2018).

UAV has developed during the last decades. They operate remotely in the form of small platform, attached completely with camera and available as small or micro aircrafts (Tziavou et al., 2018). UAV photogrammetry provides information used for image stitching. Autopilot system guarantees planned flight path, camera triggered auto-control to take a picture at every waypoint (Kumar et al., 2018). The greatest amount of information is contained in the video signal (Shashev et al., 2015, Panin et al., 2003).

With the help of UAV, the effectiveness of land monitoring together with existing infrastructures can be conducted within a short time period compare to conventional techniques, especially for urgent cases like natural disasters (Greenwood et al., 2016, Tannant et al., 2017). Recent technological developments of unmanned aerial systems (UAS), including unmanned aerial vehicles (UAV) and data processing technologies, lead to extensive use of these techniques in various fields (Scholtz et al., 2012; Colomina and Molina, 2014; Chen et al., 2016; Torok et al., 2020).

The aim of this paper is to obtain slope map of several selected study area located at Pahang Matriculation College, Kuantan, Pahang by using unmanned aerial vehicle UAV or commercially known as drone. Other than that, the measurement of these slopes will be determined such as perimeter, area, volume and more which 
considered as the main interest in this study. In addition, this paper also discusses the advantages of slope mapping using UAV compare to traditional method which proven to be the better method. Since this study collaborate with Faculty of Maritime Studies, Universiti Malaysia Terengganu, the authors would like to suggest several mapping around coastal area could be done in the future to study several effect of slope stability at coastal area, embankment at sea area, movement of ship at port and more as suggestion for future research.

\section{Research Methodology}

The study area is located at Pahang Matriculation College, Kuantan, Pahang. The site area consists of different terrain profiles. This site is completely free from any distraction and obstacle on the air for UAV to freely move around. Figure 1 show the map of study area.

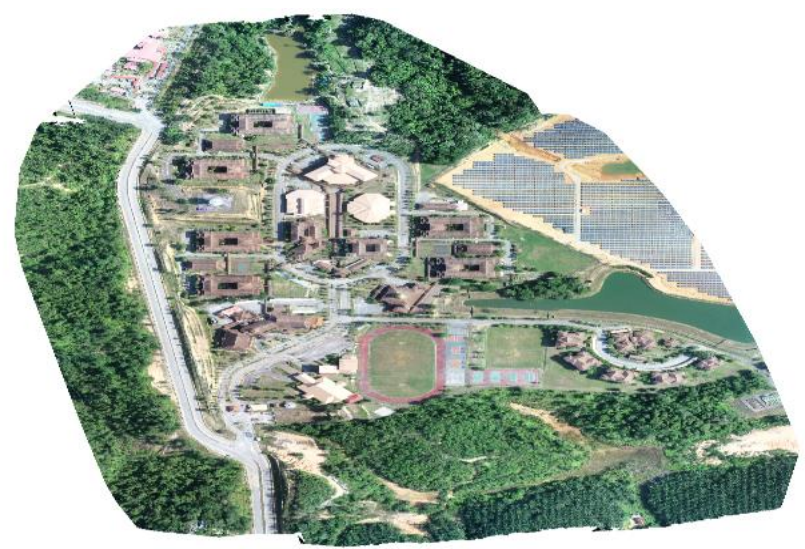

Figure 1. Location of study area

\subsection{DJI Inspire 2}

The DJI Inspire 2 weight around $3.44 \mathrm{~kg}$ make it a powerful and high technology drone. This UAV has a speed of $94 \mathrm{~km} / \mathrm{h}$ which make it pretty impressive. The max ascent speed is $6 \mathrm{~m} / \mathrm{s}$ in sport mode and the max descent speed is $4 \mathrm{~m} / \mathrm{s}$. The length of this UAV is $42.7 \mathrm{~cm}$, with height of $31.7 \mathrm{~cm}$ and width of $42.5 \mathrm{~cm}$. DJI Inspire 2 has a maximum transmission distance of $7 \mathrm{~km}$ and is capable to deliver both 1080p and 720p video. Figure 2 show the image of DJI Inspire 2. Table 2 show the specification and features of DJI Inspire 2.

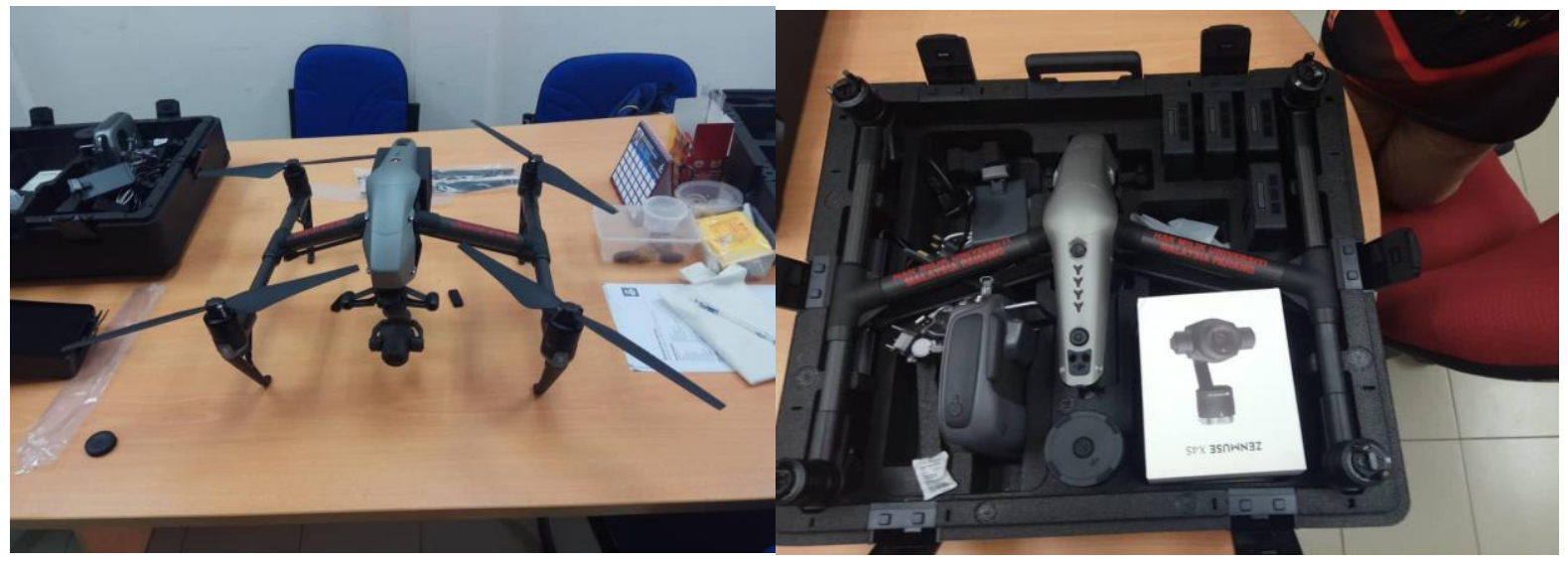

Figure 2. DJI Inspire 2

Table 2. Specification of DJI Inspire 2

\begin{tabular}{ll}
\hline Parameters & Details \\
\hline Flight time & $25-27$ minutes \\
Speed & $94 \mathrm{~km} / \mathrm{h}$ \\
Sensory range & $30 \mathrm{~m}$ \\
Battery & $98 \mathrm{Wh}$ dual battery \\
\hline
\end{tabular}




\begin{tabular}{ll}
\hline Raw video recoding & Yes \\
Ports & USB and HDMI \\
Obstacle avoidance system & Yes \\
Control range & $7 \mathrm{~km}$ \\
Video resolution & $5.2 \mathrm{~K}$ and 4K \\
Live View & $1080 \mathrm{P}$ \\
Remote controller frequency & $2.4 \mathrm{GHz}$ and $5.8 \mathrm{GHz}$ \\
& $\begin{array}{l}\text { Magnesium aluminium composite shell } \\
\text { with carbon fibre arm }\end{array}$ \\
\hline
\end{tabular}

\subsection{Image acquisition}

The normal workflow accepted for image acquisition has been used by many researchers and practitioners. Following are the steps for image acquisition as in Figure 3. The results obtained from UAV monitoring will then be transferred into global mapper version 18.1 for further analysis.

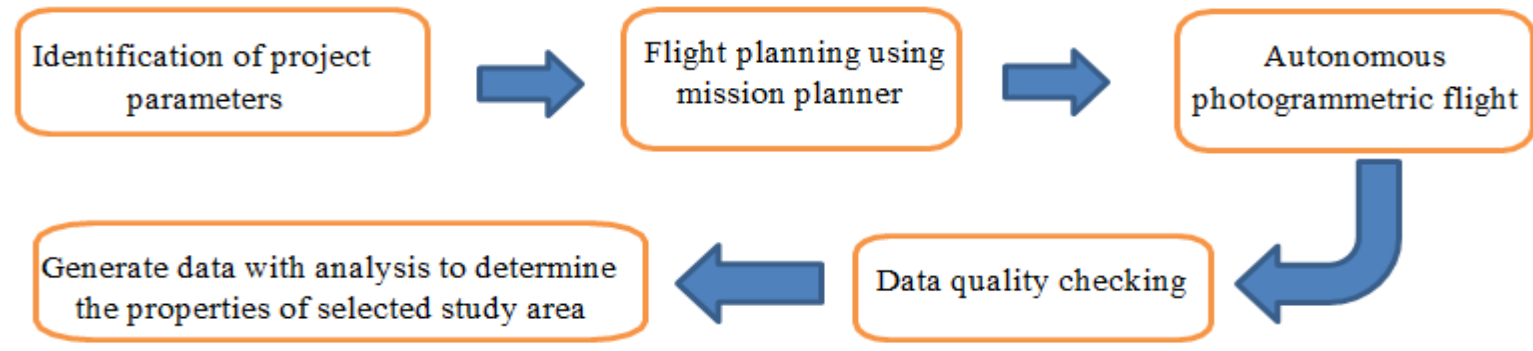

Figure 3. Workflow for data acquisition

\section{Results and Discussion}

The result of this study is presented in two types of images which are digital ortho photo and digital surface model (DSM). The ground control points (GCP) are not used in this study as it does not give much error for the results obtained. The independent ortho images are used to generate digital ortho photo in photogrammetric process. Figure 4 present the image of area A and Figure 5 show image of area B.

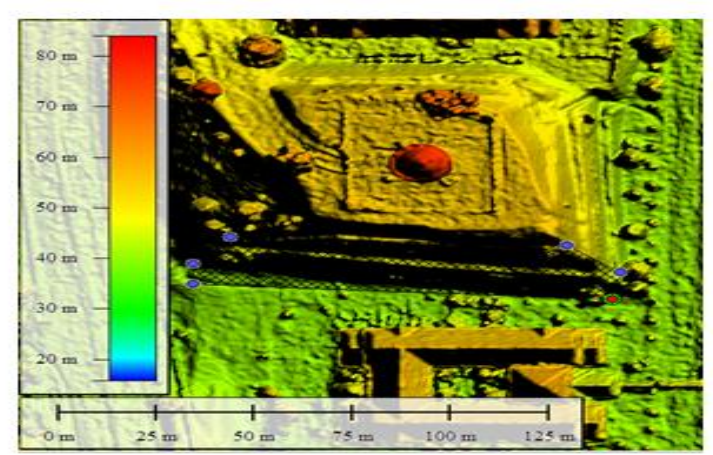

(a)

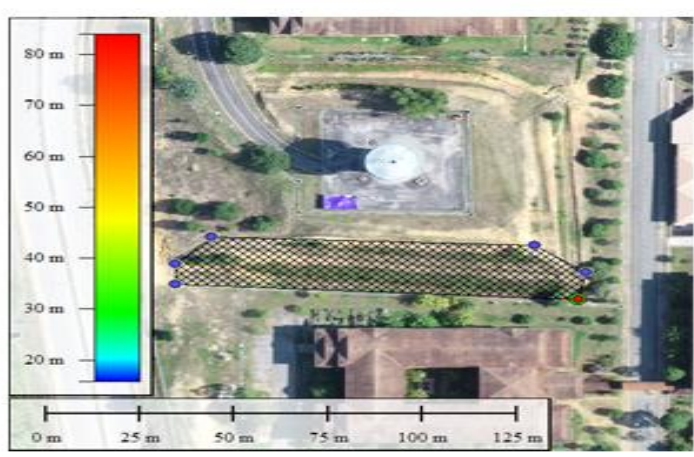

(b)

Figure 4. (a) Digital surface model (DSM) of area A, (b) Digital ortho photo of area A 


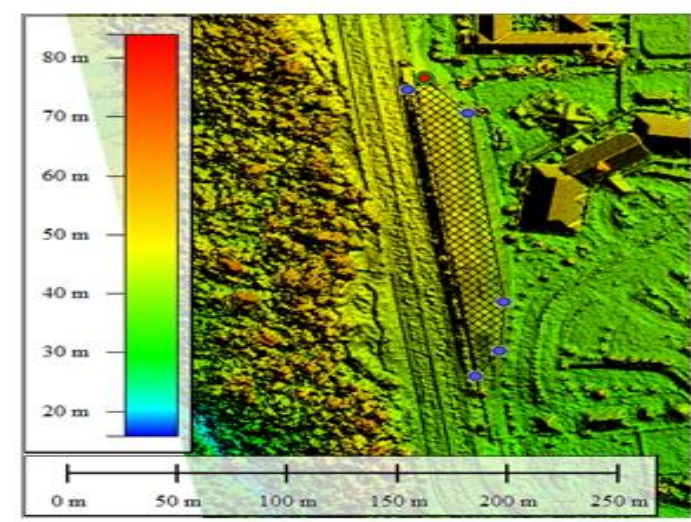

(a)

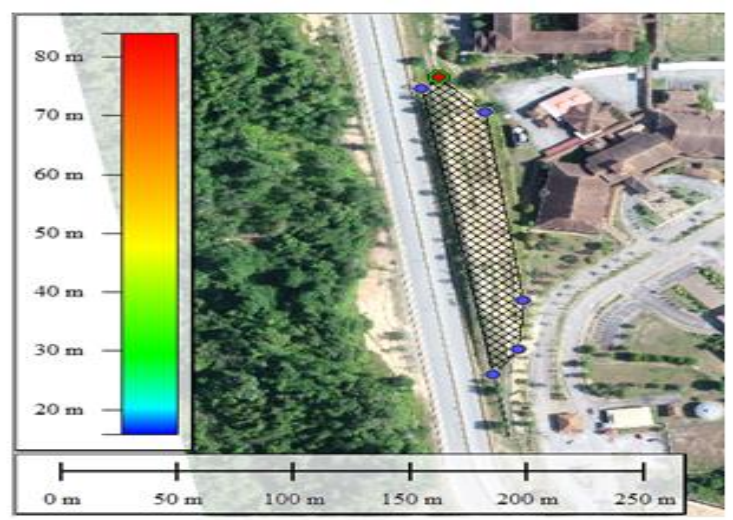

(b)

Figure 5. (a) Digital surface model (DSM) of area B, (b) Digital orthophoto of area B

The application of unmanned aerial vehicle (UAV) not only limited for area mapping, but it can also help to determine the dimension of those areas such as perimeter, area, volume and more. The uses of global mapper software version 18.1 can meet the requirement needed in order to obtain the properties of selected study area. Measurement of area A and B are shown in Figure 6 and Figure 7. The properties of area A and B are presented in Table 3 and 4.

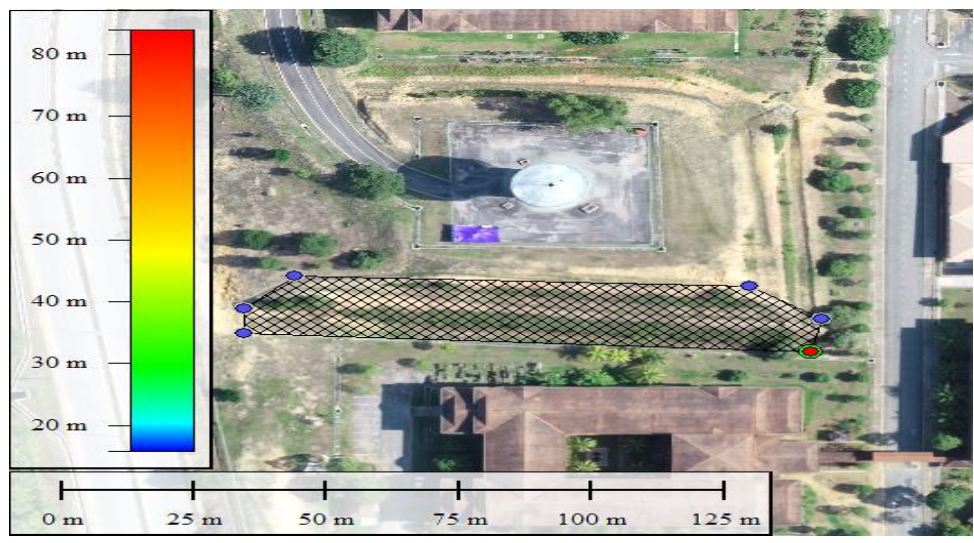

Figure 6. Dimension of area A

Table 3. Measurement of area A

\begin{tabular}{l|l}
\hline Measurement & Unit \\
\hline Total Volume & $1303.85 \mathrm{~m}^{3}$ \\
Net Volume & $138.78 \mathrm{~m}^{3}$ \\
Cut Volume & $721.31 \mathrm{~m}^{3}$ \\
Cut Area & $1174 \mathrm{~m}^{2}$ \\
Cut Area 3D & $1430 \mathrm{~m}^{2}$ \\
Fill Volume & $582.53 \mathrm{~m}^{3}$ \\
Fill Area & $910 \mathrm{~m}^{2}$ \\
Fill Area 3D & $1091 \mathrm{~m}^{2}$ \\
Enclosed Area & $2078 \mathrm{~m}^{2}$ \\
Perimeter & $243.52 \mathrm{~m}$ \\
\hline
\end{tabular}

From the table, the total volume of area A is $1303.85 \mathrm{~m}^{3}$. The net volume is $138.78 \mathrm{~m}^{3}$. The cut volume of area $A$ is $721.31 \mathrm{~m}^{3}$ whereas its cut area is $1174 \mathrm{~m}^{2}$. Besides, the cut area $3 \mathrm{D}$ is $1430 \mathrm{~m}^{2}$. The amount of fill volume of this area A is $582.53 \mathrm{~m}^{3}$ while the fill area is $910 \mathrm{~m}^{2}$. The total fill area 3D is $1091 \mathrm{~m}^{2}$. The enclosed area is $2078 \mathrm{~m}^{2}$ and the existing parameter is $243.52 \mathrm{~m}$. 


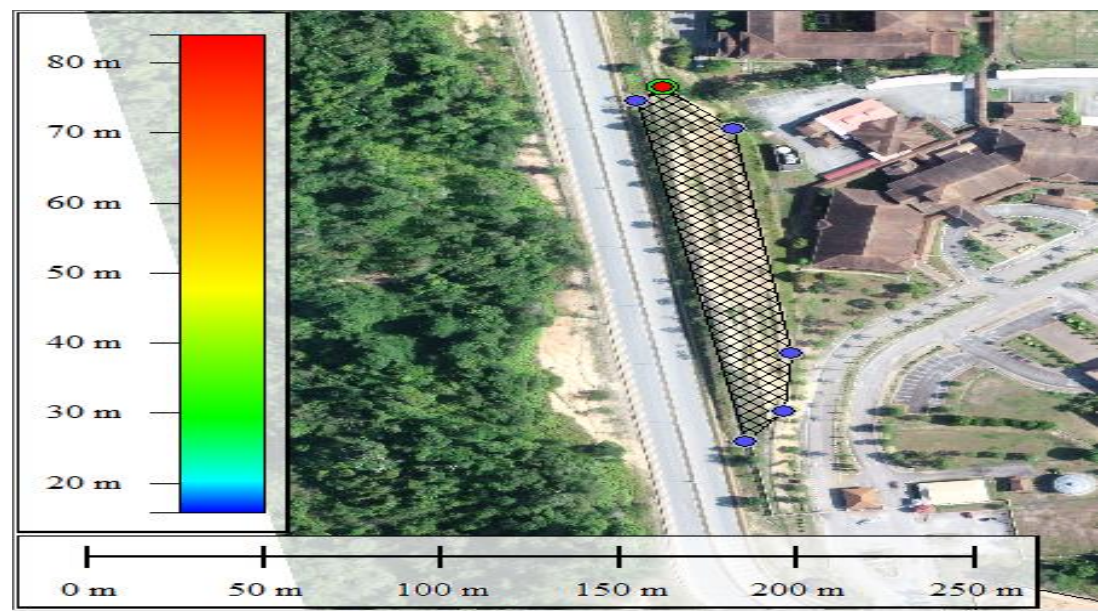

Figure 7. Dimension of area $\mathrm{B}$

Table 4. Measurement of Area B

\begin{tabular}{l|l}
\hline Measurement & Unit \\
\hline Total Volume & $3182.48 \mathrm{~m}^{3}$ \\
Net Volume & $2341.13 \mathrm{~m}^{3}$ \\
Cut Volume & $2761.80 \mathrm{~m}^{3}$ \\
Cut Area & $3439 \mathrm{~m}^{2}$ \\
Cut Area 3D & $3959 \mathrm{~m}^{2}$ \\
Fill Volume & $420.67 \mathrm{~m}^{3}$ \\
Fill Area & $634 \mathrm{~m}^{2}$ \\
Fill Area 3D & $749 \mathrm{~m}^{2}$ \\
Enclosed Area & $4061 \mathrm{~m}^{2}$ \\
Perimeter & $243.52 \mathrm{~m}$ \\
\hline
\end{tabular}

From the table, the total volume of area B is $3182.48 \mathrm{~m} 3$. The net volume is $2341.13 \mathrm{~m} 3$. The cut volume of the area B is $2761.80 \mathrm{~m} 3$ whereas its cut area is $3439 \mathrm{~m} 2$. Besides, the cut area 3D is $3959 \mathrm{~m} 2$. The amount of fill volume of this area B is $420.67 \mathrm{~m} 3$ while the fill area is $634 \mathrm{~m} 2$. The total fill area 3D is $749 \mathrm{~m} 2$. The enclosed area of area B is $04061 \mathrm{~m} 2$ and the existing parameter is $243.52 \mathrm{~m}$.

Table 5 shows the comparison of slope mapping between Unmanned Aerial Vehicle (UAV) and traditional method. First the comparison in term of area scale where unmanned aerial vehicle (UAV) act as aerial photogrammetric technique to effectively generate medium to extra-large scale mapping and other diversified applications especially for a small area which has limited budget and time compare to traditional method which only generate small scale mapping.

The UAV method allows surveyors to do works in a short period of time and required minimum worker or only one worker which proven to be a better method of mapping compare to those suggested by Fatzpatrick (2016) which using manned aircraft; Siebert and Teizer (2014) which using tachymetry (theodolite) surveying techniques and Tahar (2018); Malehmir et al. (2017) which using rotary wing UAVs survey. They stated that this traditional method is more time consuming and required more workers.

This UAV technique is one of the alternatives for a faster way in data acquisition, easy and safe while according to Beretta et al. (2018) using laser scanning; Sebbane (2018) using GPS point survey; Siebert and Teizer (2014) using tachymetry (theodolite) surveying techniques described that those method consume lot of time for data acquisition and processing, much complicated and unsafe to workers because of challenging site due to factor of topography.

UAV-acquired datasets have better resolutions in both temporal and spatial aspects with the high quality, cheaper and impressive level of details in the outputs compare using laser scanning survey method is expensive, generates low-quality products and unimpressive level of details in the outputs (Beretta et al., 2018). 
Muhammad Farhan Zolkepli, Norlinda Mohamad Rozar, Mohd Fakhrurrazi Ishak*, Mohamad Hazeem Sidik, Nurul Amira Syuhada Ibrahim, Muhammad Syamsul Imran Zaini

Table 5. Comparison of slope mapping using UAV and traditional method

\begin{tabular}{l|l|l}
\hline Comparison & $\begin{array}{l}\text { Unmanned Aerial Vehicle } \\
\text { UAV) Method }\end{array}$ & Traditional Method \\
\hline Area & Medium to extra large & Small \\
Time consuming & Short & Long \\
Usability & Easy & Much Complex \\
Data quality & High & Low \\
Cost & Cheap & Expensive \\
Worker & Minimum (one is more than & Maximum (depend on site) \\
Potential hazard to man & Safe & Unsafe (especially in high and \\
Data acquisition & Fast & hilly region) \\
Slow
\end{tabular}

\section{Conclusion}

From this study, the uses of UAV has proven to be very effective such as low costing, low time consuming, easily to operate and can gather huge amount of data within short time interval for slope mapping. This modern technology will help in research and also commercial works which make work easier and faster. In this study, with the combination of data from UAV and also established software provide researchers with important parameters and information about geological and topography of study area. Other than that, the properties of the study area such as its perimeter, area, volume and more can be obtain precisely. Mapping using UAV prove to give better impact when compare to mapping using previous traditional method.

As suggested by Nurdin et al. (2019); Darwin et al. (2014); Kaamin et al. (2018), coastal mapping using unmanned aerial vehicle (UAV) can be considered very helpful and effective due to challenge face if conducting mapping using traditional method. Due to huge coastal area, normal mapping considered very challenging and for worst may contribute to fatality for those involve in mapping work.

The coastal zone area is the most valuable asset for inland transport mode and waterways of mobility and transport, In Malaysia, to promote and strengthen the inland and waterway in the transport system is by facilitating its integration into intermodal logistics chain by widen the path of the transport. Thus, infrastructure construction and maintenance are highly required. In the requirements, one of the technologies and technical are recommended is by an application of UAV. As discussed above, it was recognised and used for slope mapping in building development and believed by use of it will assist for constructions of roads, railways, bridges, tunnels, terminals, ports, and airports without limiting the geographical area.

\section{References}

1. Beretta, F., Shibata, H., Cordova, R., Peroni, R. d. L., Azambuja, J. and Costa, J.F.C.L. (2018). Topographic Modelling using UAVs Compared with Traditional Survey Methods in Mining. REM, Int. Eng. J. 71:3, 1-11.

2. Bondarchuk, A.S. (2018). System of Technical Vision for Autonomous Unmanned Aerial Vehicles. IOP Conf. Ser.: Mater. Sci. Eng. 363, 012027.

3. Chen, J., Dowman, I.; Li, S.; Li, Z.; Madden, M.; Mills, J.; Paparoditis, N.; Rottensteiner, F.; Sester, M. and Toth, C. (2016). Information From Imagery: ISPRS Scientific Vision and Research Agenda. ISPRS J. Photogramm. Remote Sens. 115, 3-21.

4. Colomina, I., and Molina, P. (2014). Unmanned Aerial Systems for Photogrammetry and Remote Sensing: A review. ISPRS J. Photogramm. Remote Sens. 92, 79-97.

5. Darwin, N., Ahmad, A. and Zainon, O. (2014). The Potential of Unmanned Aerial Vehicle for Large Scale Mapping of Coastal Area. IOP Conference Series: Earth and Environmental Science. 18, 012031.

6. Eid, B.M., Chebil, J., Albatsh, F. and Faris, W.F. (2013). Challenges of Integrating Unmanned Aerial Vehicles in Civil Application. IOP Conf. Ser.: Mater. Sci. Eng. 53, 012092.

7. Fitzpatrick, B.P. (2016). Unmanned Aerial Systems for Surveying and Mapping: Cost Comparison of UAS versus Traditional Methods of Data Acquisition. Master of Science. University of Southern California.

8. Greenwood, W., Zekkos, D., Lynch, J., Bateman, J., Clark, M., Chamlagain, D. (2016). UAV Based 3-D Characterization of Rock Masses and Rock Slides in Nepal. In $50^{\text {th }}$ US Rock 
Mechanics/Geomechanics Symposium, American Rock Mechanics Association, Houstan, TX, 2629 June.

9. Ismail, M.A.M., Kumar, N.S., Abidin, M.H.Z. and Madun, A. (2018). Systemic Approach to Elevation Data Acquisition for Geophysical Survey Alignments in Hilly Terrains using UAVs. $J$. Phys.: Conf. Ser. 995, 012104.

10. Kaamin, M., Daud, M. E., Sanik, M. E., Ahmad, N. F. A., Mokhtar, M., Ngadiman, N. and Yahya, F. R. Mapping Shoreline Position using Unmanned Aerial Vehicle. AIP Conference Proceedings 2016, 020063 (2018); https://doi.org/10.1063/1.5055465

11. Kumar, N.S., Ismail, M.A.M., Sukor, N.S.A. and Cheang, W. (2018). Geohazard Reconnaissance Mapping for Potential Rock Boulder fall using Low Altitude UAV Photogrammetry. IOP Conf. Ser.: Mater. Sci. Eng. 352, 012033.

12. Kumar, N.S., Ismail, M.A.M., Sukor, N.S.A. and Cheang, W. (2018). Method for the Visualization of Landform by mapping using Low Altitude UAV Application. IOP Conf. Ser.: Mater. Sci. Eng. 352, 012032.

13. Malehmir, A. \& Dynesius, L. \& Paulusson, K. \& Paulusson, A. \& Johansson, H. \& Bastani, M. \& Wedmark, M. \& Marsden, P. (2017). The potential of rotary- wing UAV-based magnetic surveys for mineral exploration: A case study from central Sweden. The Leading Edge. 36:7. 552-557. doi: 10.1190/tle36070552.1.

14. Nurdin, N., Inaku, D. F., Rasyid, A. R., Jalil,A. R., Alimuddin, A., Agus, Akbar, M, A. S. and Al Azizi, S. Q. (2019). Participatory Mapping and Unmanned Aerial Vehicle (UAV) Images for Developing Village Level Coastal Geoinformation. IOP Conference Series: Earth and Environmental Science. 370, 012003.

15. Panin, S.V., Syryamkin, V.I. and Glukhih, A.I. (2003). Avtometriya. (4). 79-92.

16. Park, S., Lee, H. and Chon, J. (2019). Sustainable Monitoring Coverage of Unmanned Aerial vehicle Photogrammetry According to Wing Type and Image Resolution. Environmental Pollution. 247. 340-348.

17. Scholtz, A., Kaschwich, C.; Krüger, A.; Kufieta, K.; Schnetter, P.; Wilkens, C.-S.; Krüger, T. and Vörsmann, P. (2012). Development of a New Multi-Purpose UAS for Scientific Application. ISPRS Int. Arch. Photogramm. Remote Sens. Spat. Inf. Sci. XXXVIII-1/C22, 149-154.

18. Sebbane, Y.B. (2018). Introduction to The Intelligent Autonomy of UAVs: Advanced Missions and Future Use (First edition). Boca Raton, FL Taylor \& Francis Group.

19. Shashev, D.V., Shidlovskiy, S.V., Syriamkin, V.I. and Yurchenko, A.V. (2015). IOP Conf. Ser.: Mater. Sci. Eng. 81, 012101.

20. Siebert, S. and Teizer, Dr.J. (2014). Mobile 3D Mapping for Surveying Earthwork using an Unmanned Aerial Vehicle (UAV). Automation in Construction. 41, 1- 14.

21. Tahar, K. N., Ahmad, A., Wan Mohd Akib, W. A. A and Udin, W. S. (2011). Unmanned Aerial Vehicle Technology For Large Scale Mapping. ISG \& ISPRS. 27-29, 2011. Shah Alam, MALAYSIA

22. Tannant, D.D., Giordan, D. and Morgenroth, J. (2017). Characterization and Analysis of a Translational Rockslide on a Stepped Planar Slip Surface. Eng. Geol. 220, 144-151.

23. Torok, A., Bogoly, G., Somogyi, A. and Lovas, T. (2020). Application of UAV in Topographic Modelling and Structural Geological Mapping of Quarries and Their Surroundings-Delineation of Fault-Bordered Raw Material Reserves. Sensors. 20 (489). 1-19.

24. Turner, I.L., Harley, M.D., Drummond, C.D. (2016). UAVs for Coastal Surveying. Coast Eng. $114,19-24$.

25. Tziavou, O., Pytharouli, S. and Souter, J. (2018). Unmanned Aerial Vehicle (UAV) based Mapping in Engineering Geological Surveys: Considerations for Optimum Results. Engineering Geology, 232, 12-21. 